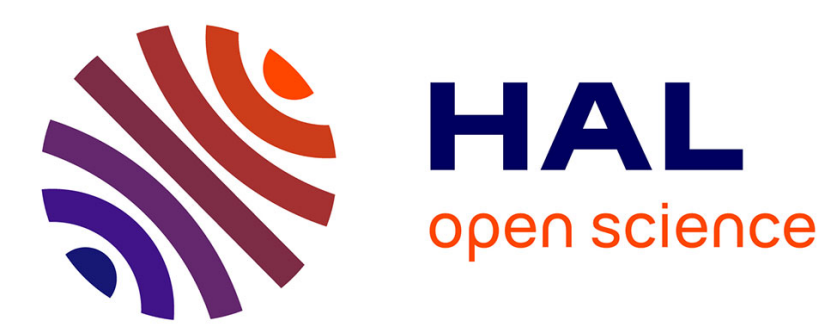

\title{
Absorption Spectra of Aryl Thiol-Coated Silver Nanoclusters: A Time-Dependent Density-Functional Study
}

Benjamin Bousquet, Mohamed Cherif, Kunqiang Huang, Franck Rabilloud

\section{- To cite this version:}

Benjamin Bousquet, Mohamed Cherif, Kunqiang Huang, Franck Rabilloud. Absorption Spectra of Aryl Thiol-Coated Silver Nanoclusters: A Time-Dependent Density-Functional Study. Journal of Physical Chemistry C, 2015, 119, pp.4268-4277. 10.1021/jp512209p . hal-02308147

\section{HAL Id: hal-02308147 https://univ-lyon1.hal.science/hal-02308147}

Submitted on 18 Jan 2020

HAL is a multi-disciplinary open access archive for the deposit and dissemination of scientific research documents, whether they are published or not. The documents may come from teaching and research institutions in France or abroad, or from public or private research centers.
L'archive ouverte pluridisciplinaire HAL, est destinée au dépôt et à la diffusion de documents scientifiques de niveau recherche, publiés ou non, émanant des établissements d'enseignement et de recherche français ou étrangers, des laboratoires publics ou privés. 


\section{Absorption Spectra of Aryl Thiol Coated Silver}

\section{Nanoclusters: A Time-Dependent Density Functional Study}

Benjamin Bousquet, Mohamed Cherif, Kunqiang Huang, and Franck Rabilloud*

Institut Lumière Matière, UMR5306 Université Claude Bernard Lyon 1 - CNRS, Université de Lyon 69622 Villeurbanne Cedex, France

E-mail: franck.rabilloud@univ-lyon1.fr

${ }^{*}$ To whom correspondence should be addressed 


\begin{abstract}
We present a theoretical study of the optical response of silver clusters, $\operatorname{Ag}_{n} n=4,8,10,20$, complexed with the aryl thiols $\mathrm{FC}_{6} \mathrm{H}_{4} \mathrm{~S}^{-}$and $\mathrm{CH}_{3} \mathrm{C}_{6} \mathrm{H}_{4} \mathrm{~S}^{-}$in an aqueous solution. The absorption spectra are found to be strongly modified by the adsorption of aromatic thiols with a red-shift of the plasmon-like band, and the emergence of new excitations due to chargetransfer transitions between thiols and the metal cluster. Our results highlight the influence of the molecular orientation of thiol ligands relative to the cluster surface on the excitations. We also analyze the appropriateness of substituting a thiol molecule by SH group. Calculations have been performed using the time-dependent density functional theory (TDDFT).
\end{abstract}

\title{
Introduction
}

The interaction between light and metal nanoparticles is a topic of great fundamental and technological interest with potential applications in many fields, such as nanoelectronics, nanooptics, biosciences. ${ }^{1}$ In particular, the noble metal nanoparticles are characterized by their ability to support surface plasmons. However, their optical properties depend, amongst others, on the particle' shape $^{2-5}$ and the particle' size. ${ }^{6-15}$ For example, small silver clusters have molecular-like optical transitions and their spectra are composed from several narrow or broad peaks whose the positions depend on the number of atoms that compose the cluster. ${ }^{8,16-18}$ As silver clusters grow, they lose these molecular properties and develop a large, unique absorption band in the UV-visible region. The emergence of this plasmon-like band has been showed to occur for clusters of about 20 silver atoms. ${ }^{12,19}$ The plasmon band is redshifted as the cluster' size increases. ${ }^{6,7,9,20,21}$ While mediumsized clusters (several tens of atoms) present a main band near $4 \mathrm{eV}, 8,9,22,23$ the nanoparticles of about 8 nanometers in diameter show a strong optical absorption band near $3.2 \mathrm{eV} .^{7,21}$ Let us note that the optical properties can be also modified by mixing several elements together. ${ }^{23-27}$

Large efforts are engaged in the synthesis methods in order to control the size, shape and the atomic arrangement of metal nanoparticles, on which depend their physical and chemical properties. As free metal nanoparticles are inherently unstable against thermal and chemical decom- 
position, one had to develop techniques to stabilize them. When metal clusters are produced in gas phase, they can be accumulated and stabilized in a protective solid matrix. ${ }^{8,18,28}$ If they are synthesized in solution, the stabilization of clusters may be ensured by the surface adsorption of strong ligands, like thiols, resulting in thiolate monolayer-protected clusters, consisted of a metallic core that is surrounded by ligands. ${ }^{29-34}$ The adsorbed molecules provide original and controllable properties to the clusters, mainly in the field of optical absorption or emission, and enable a chemical fonctionalization. However, the optical properties of metal nanoparticles can be affected by the adsorbate. ${ }^{14,29,35-37}$ The plasmon resonances of silver nanoclusters of 2-3 nanometers in diameter protected by 2-phenylethanethiol, 4-fluorothiophenol, L-glutathione, were showed to be strongly redshifted in comparison to the vacuum value (from about $3.8 \mathrm{eV} \mathrm{nm}$ to about 2.7 eV). ${ }^{32}$ Interestingly, Bakr et al ${ }^{29}$ were able to create aryl thiol coated silver nanoparticles that show intense and broad non-plasmonic optical properties at intermediate size (diameter of silver core of about $1.3 \mathrm{~nm}$ ). Instead of the expected plasmon band, these nanoclusters present eight distinct absorption bands covering the entire visible spectrum in the $375-850 \mathrm{~nm}$ range. They were prepared in solution through the reduction of silver salt in presence of different aryl thiol ligands: 4-fluorothiophenol, 3-fluorothiophenol, 2-fluorothiophenol, 4-methylbenzene-1,2-dithiol, 4-methylthiophenol, (2-mercapto-5-methylphenyl)methanol. The nanoclusters, which are likely to be negatively charged, were shown to be stable in solution. Later, they were identified with the molecular formula of $\mathrm{Ag}_{44}(\mathrm{SR})_{30}{ }^{4-}$ by mass spectrometry and by sedimentation velocityanalytical ultracentrifugation. ${ }^{38}$ Desireddy ${ }^{39}$ and Yang ${ }^{40}$ have independently published the crystal structure measured by X-ray crystallography. The structure can be roughly described as a compact, quasi-spherical $\mathrm{Ag}_{32}$ core capped by six $\mathrm{Ag}_{2} \mathrm{~S}_{5}$ units. These six capping units are somewhat complex structures, they are composed by four $\mathrm{S}$ atoms bridged by a pair of $\mathrm{Ag}$ atoms, which are in turn bridged by a terminal $\mathrm{S}$ atom. Each sulfur is bonded to several $\mathrm{Ag}$ atoms, and only twelve $\mathrm{Ag}$ atoms are not in contact with sulfur. Beside, the negative charge of -4 par nanoparticle was deduced to the charge of positive conterions in the crystal. Then the high stability of $\operatorname{Ag}_{44}(\mathrm{SR})_{30}{ }^{4-}$ was attributed to a closed-shell 18 -electron configuration. ${ }^{38-40}$ The electronic properties were char- 
acterized by calculations ${ }^{39}$ performed in the framework of density-functional theory, while the absorption spectra were simulated ${ }^{40,41}$ using the time-dependent density-functional theory (TDDFT). In particular, calculations have shown the significant contribution from the aromatic ligands in the optical transitions in the visible range, and also the need to take into account the negative charge of the cluster. Others different crystal structures based on the motif of $\mathrm{Ag}_{44}(\mathrm{SR})_{30}{ }^{4-}$ were recently reported with different compositions of the metal core ( $\mathrm{Ag}, \mathrm{AgAu}, \mathrm{AuCu})$ and different ligands ${ }^{40,42}$ Thess experimental works give a good opportunity to investigate the transition from plasmon-like to molecular-like behavior induced by the increasing ligand coating of a metallic cluster, and were the motivation of the present work.

Here, we present a theoretical study of small silver clusters, $\operatorname{Ag}_{n} n=4,8,10,20$, complexed with the aromatic ions $\mathrm{FC}_{6} \mathrm{H}_{4} \mathrm{~S}^{-}$and $\mathrm{CH}_{3} \mathrm{C}_{6} \mathrm{H}_{4} \mathrm{~S}^{-}$in aqueous solutions. The hydrogen attached to the thiol group in the free molecule is considered to be already detached and not included in our calculations. As the complexes are expected to be negatively charged in solution, we consider here some anionic complexes namely $\left(\mathrm{FC}_{6} \mathrm{H}_{4} \mathrm{~S}^{-}\right)_{m}-\mathrm{Ag}_{n}$ and $\left(\mathrm{CH}_{3} \mathrm{C}_{6} \mathrm{H}_{4} \mathrm{~S}^{-}\right)_{m}-\mathrm{Ag}_{n}$, with $m=1-4$ and $n=4,8,10$, together with $\left[\left(\mathrm{FC}_{6} \mathrm{H}_{4} \mathrm{~S}\right)_{m}-\mathrm{Ag}_{20}\right]^{2-}$ and $\left[\left(\mathrm{CH}_{3} \mathrm{C}_{6} \mathrm{H}_{4} \mathrm{~S}\right)_{m}-\mathrm{Ag}_{20}\right]^{2-}$ clusters. We first determine the most favourable adsorption sites in the framework of density-functional theory (DFT). For the geometry optimization, the initial geometries are build with the lowest-energy isomer of silver clusters in gas phase on which one or several molecules are anchored, but all atoms are free to relax in the process. Then, for each silver cluster, we study the evolution of its UV-visible absorption spectrum with the number of thiol ligands. In all simulations, the thiol ligand prefers to adopt a down position in which the phenyl ring is in proximity with the metal cluster. However, we also performed simulations enforcing the molecules into an upright position. We show that the molecular orientation of thiol ligands relative to the cluster surface affects the optical response. Spectra are calculated using the TDDFT method ${ }^{43-45}$ with a long-range corrected density functional in order to give a more suitable description of charge-transfer excitations. Details of our computational methods are given in the next section. 


\section{Computational method}

All calculations have been performed using the Gaussian09 suite of programs. ${ }^{46}$ Pre- and postprocessing operations were performed by using the graphical interface Gabedit. ${ }^{47}$ Silver atoms were described through a relativistic effective core potential (RECP) so that only 19 valence electrons were treated explicitly and the associated basis set. ${ }^{48}$ For sulfur, oxygen, carbon, and hydrogen atoms, all electrons were explicitly treated using a full double-zeta quality basis set. ${ }^{49}$ We have checked the reliability of the basis set by comparing the optical spectra of the complexed $\mathrm{Ag}_{4}$ cluster with those obtained using the quadruple-zeta quality with polarization def2-QZVP basis sets for all atoms. ${ }^{50}$ All calculation have been performed using the exchange and correlation density functionals named LC-M06L. LC-M06L is obtained by applying a long-range correction ${ }^{51}$ to the meta-GGA M06L ${ }^{52}$ functional ("meta" denotes the inclusion of kinetic energy density, which depends on local derivatives of the spin orbitals). The parametrization of M06L was performed to reproduce some properties of metallic and organometallic systems. LC-M06L contains $0 \%$ Hartree-Fock exchange at short range and $100 \%$ at long range. The range separation parameter was 0.47 . Recent works ${ }^{53,54}$ have shown that this functional gives good performances for simulating the absorption spectra of silver clusters. Some calculations have been performed using the hybrid functional $\omega \mathrm{B} 97 \mathrm{X}-\mathrm{D}^{55}$ which contains an increasing amount of Hartree-Fock exchange at long range (from $22 \%$ at short range to $100 \%$ at long range), and also includes empirical dispersion corrections. Spectra are found to be very similar to those obtained at LC-M06L level (some spectra are given in Supplementary information).

Complexes were studied in an aqueous solution. The solvant used in our calculations was the water simulated with a polarizable continuum model (PCM). ${ }^{56,57}$

The initial geometry of silver clusters was taken from a previous work ${ }^{12}$ and locally reoptimized at the present level of calculation. One or several charged molecules were adsorbed on $\mathrm{Ag}_{n}$ clusters. Many adsorption sites via S atom and several molecular orientations have been explored. All optimization were carry out without symmetry constraints ( $C_{1}$ point group) and all atoms are free to relax. In the case of $\mathrm{Ag}_{20}$, to reduce the computational cost, the geometry optimization was 
performed using the density fitting formalism ${ }^{58}$ and auxiliary basis sets to approximate Coulomb potentials ${ }^{59,60}$ and also the positions of silver atoms were kept fixed.

The calculation of the optical properties in an aqueous solution has been performed in the framework of the time-dependent density functional theory. All spectra presented in the figures below give both a stick spectrum with the oscillator strength as a function of the excitation energy, and a curve obtained by a Lorentzian broadening with a full width of half-height of $0.05 \mathrm{eV}$.

\section{Results}

\section{Optimized structures and energetics}

The structures for both charged $\mathrm{FC}_{6} \mathrm{H}_{4} \mathrm{~S}^{-}$and $\mathrm{CH}_{3} \mathrm{C}_{6} \mathrm{H}_{4} \mathrm{~S}^{-}$molecules are given in Figure 1. The lowest-energy isomers of $\left(\mathrm{FC}_{6} \mathrm{H}_{4} \mathrm{~S}^{-}\right)_{m}-\mathrm{Ag}_{n}$ and $\left(\mathrm{CH}_{3} \mathrm{C}_{6} \mathrm{H}_{4} \mathrm{~S}^{-}\right)_{m}-\mathrm{Ag}_{n}$, with $n=4,8,10$ and $m=$ $1-4$, can be shown in Figures 2,3,4. They are very similar for both families with the same adsorption site of molecules and the same orientation of aromatic cycles. While the anchoring of thiol ligands to the silver cluster occurs via a top position for small $\mathrm{Ag}_{n}$ clusters, it occurs via bridge and face positions on $\mathrm{Ag}_{20}$ (Figure 5). In all cases, the thiol ligand prefers to adopt a flatlying position in which the aromatic ring is in contact with the metal cluster. The standing-up position in which the ligand binds to the silver cluster into a perpendicular manner was found not to be stable, though they are expected to be favored for large, fully covered metal clusters because of the intermolecular interactions and the high surface density. In our calculations, $\mathrm{Ag}_{4}$ and $\mathrm{Ag}_{8}$ are not able to bind more than four molecules. Consequently, there is no intermolecular interactions for stabilizing the ligands into an upright position. For each complexed group, the S-Ag bond slightly increases (from 2.47 to $2.67 \AA$ ) with the size of silver cluster and the number of adsorbed molecules. The adsorption energy per molecule are calculated to be in the 2.1-3.4 eV range (Table 1). It generally increases with the size of the silver clusters, but it decreases as the number of ligands increases. The Ag-S bonding are strong, and each species is very stable. The atomic charges have been estimated through a natural population analysis (NPA). ${ }^{61}$ They show 
that each adsorbed molecule transfers a charge of about -0.3 au to the metal cluster, leading to a total charge on metal part of $-1.16,-1.38$, and -1.46 when four ligands bind $\mathrm{Ag}_{4}, \mathrm{Ag}_{8}$ and $\mathrm{Ag}_{10}$ respectively. The charge on the sulfur atom is about -0.5 au in contact with the silver cluster, while it is -0.68 au in the case of isolated molecule.

Table 1: Binding energy per molecule for both $\left(\mathrm{FC}_{6} \mathrm{H}_{4} \mathrm{~S}^{-}\right)_{m}-\mathrm{Ag} \mathrm{g}_{n}$ and $\left(\mathrm{CH}_{3} \mathrm{C}_{6} \mathrm{H}_{4} \mathrm{~S}^{-}\right)_{m}-\mathrm{Ag}_{n}$ complexes with $m=1-4$ and $n=4,8,10$.

\begin{tabular}{ll|ll}
\hline Complex & $\mathrm{E}_{\text {bind }} / m(\mathrm{eV})$ & Complex & $\mathrm{E}_{\text {bind }} / m(\mathrm{eV})$ \\
$\left(\mathrm{FC}_{6} \mathrm{H}_{4} \mathrm{~S}^{-}\right)-\mathrm{Ag}_{4}$ & 2.70 & $\left(\mathrm{CH}_{3} \mathrm{C}_{6} \mathrm{H}_{4} \mathrm{~S}^{-}\right)-\mathrm{Ag}_{4}$ & 2.87 \\
$\left(\mathrm{FC}_{6} \mathrm{H}_{4} \mathrm{~S}^{-}\right)_{2}-\mathrm{Ag}_{4}$ & 2.55 & $\left(\mathrm{CH}_{3} \mathrm{C}_{6} \mathrm{H}_{4} \mathrm{~S}^{-}\right)_{2}-\mathrm{Ag}_{4}$ & 2.69 \\
$\left(\mathrm{FC}_{6} \mathrm{H}_{4} \mathrm{~S}^{-}\right)_{3}-\mathrm{Ag}_{4}$ & 2.31 & $\left(\mathrm{CH}_{3} \mathrm{C}_{6} \mathrm{H}_{4} \mathrm{~S}^{-}\right)_{3}-\mathrm{Ag}_{4}$ & 2.48 \\
$\left(\mathrm{FC}_{6} \mathrm{H}_{4} \mathrm{~S}^{-}\right)_{4}-\mathrm{Ag}_{4}$ & 2.15 & $\left(\mathrm{CH}_{3} \mathrm{C}_{6} \mathrm{H}_{4} \mathrm{~S}^{-}\right)_{4}-\mathrm{Ag}_{4}$ & 2.24 \\
\hline$\left(\mathrm{FC}_{6} \mathrm{H}_{4} \mathrm{~S}^{-}\right)-\mathrm{Ag}_{8}$ & 2.83 & $\left(\mathrm{CH}_{3} \mathrm{C}_{6} \mathrm{H}_{4} \mathrm{~S}^{-}\right)-\mathrm{Ag}_{8}$ & 3.05 \\
$\left(\mathrm{FC}_{6} \mathrm{H}_{4} \mathrm{~S}^{-}\right)_{2}-\mathrm{Ag}_{8}$ & 2.70 & $\left(\mathrm{CH}_{3} \mathrm{C}_{6} \mathrm{H}_{4} \mathrm{~S}^{-}\right)_{2}-\mathrm{Ag}_{8}$ & 3.13 \\
$\left(\mathrm{FC}_{6} \mathrm{H}_{4} \mathrm{~S}^{-}\right)_{3}-\mathrm{Ag}_{8}$ & 2.87 & $\left(\mathrm{CH}_{3} \mathrm{C}_{6} \mathrm{H}_{4} \mathrm{~S}^{-}\right)_{3}-\mathrm{Ag}_{8}$ & 3.02 \\
$\left(\mathrm{FC}_{6} \mathrm{H}_{4} \mathrm{~S}^{-}\right)_{4}-\mathrm{Ag}_{8}$ & 2.74 & $\left(\mathrm{CH}_{3} \mathrm{C}_{6} \mathrm{H}_{4} \mathrm{~S}^{-}\right)_{4}-\mathrm{Ag}_{8}$ & 2.95 \\
\hline$\left(\mathrm{FC}_{6} \mathrm{H}_{4} \mathrm{~S}^{-}\right)-\mathrm{Ag}_{10}$ & 3.37 & & \\
$\left(\mathrm{FC}_{6} \mathrm{H}_{4} \mathrm{~S}^{-}\right)_{2}-\mathrm{Ag}_{10}$ & 2.59 & & \\
$\left(\mathrm{FC}_{6} \mathrm{H}_{4} \mathrm{~S}^{-}\right)_{3}-\mathrm{Ag}_{10}$ & 2.56 & & \\
$\left(\mathrm{FC}_{6} \mathrm{H}_{4} \mathrm{~S}^{-}\right)_{4}-\mathrm{Ag}_{10}$ & 2.52 & $\left(\mathrm{CH}_{3} \mathrm{C}_{6} \mathrm{H}_{4} \mathrm{~S}^{-}\right)_{4}-\mathrm{Ag}_{10}$ & 3.24 \\
\hline
\end{tabular}

\section{Absorption spectra}

The absorption spectra for both charged $\mathrm{FC}_{6} \mathrm{H}_{4} \mathrm{~S}^{-}$and $\mathrm{CH}_{3} \mathrm{C}_{6} \mathrm{H}_{4} \mathrm{~S}^{-}$molecules in an aqueous solution are calculated to be somewhat similar with strong transitions at 4.63, 5.30, 6.94, 7.08, 8.02, 8.22 eV for $\mathrm{FC}_{6} \mathrm{H}_{4} \mathrm{~S}^{-}$and at 4.73, 5.33, 6.88, 6.99, 7.85, 8.05 eV for $\mathrm{CH}_{3} \mathrm{C}_{6} \mathrm{H}_{4} \mathrm{~S}^{-}$(Figure 1). To the best of our knowledge, no experimental data have been published. For both species, the excitations below $6 \mathrm{eV}$ are mainly associated to transitions from the $p$-orbital of the sulfur atom with small contribution from the $p$-orbital of carbon atoms to $p$-orbitals localized on the carbon atoms of the aromatic cycle. The excitations above $6 \mathrm{eV}$ implies essentially $p$-orbitals on the carbon atoms of the aromatic cycle.

The UV-visible absorption spectra calculated in an aqueous solution for the most stable isomer of both $\left(\mathrm{FC}_{6} \mathrm{H}_{4} \mathrm{~S}^{-}\right)_{m}-\mathrm{Ag}_{n}$ and $\left(\mathrm{CH}_{3} \mathrm{C}_{6} \mathrm{H}_{4} \mathrm{~S}^{-}\right)_{m}-\mathrm{Ag}_{n}(m=1-4, n=4,8,10)$ complexes are shown 
in Figures 2,3,4 together with the spectra of pure silver clusters. Spectra of bare and complexed $\mathrm{Ag}_{20}$ cluster are shown in Figure 5. The present spectra of pure $\operatorname{Ag}_{n}$ clusters in an aqueous solution show a red-shift compared with spectra previously calculated at the same level of theory in the gas phase. ${ }^{53}$ For $\mathrm{Ag}_{4}$, the main transitions in the aqueous solution are calculated at 2.74 and $3.92 \mathrm{eV}$ (Figure 2), where as they were found at 3.12 and $4.30 \mathrm{eV}$ in gas phase. For $\mathrm{Ag}_{8}$, the strong triply degenerated peak at $3.85 \mathrm{eV}$ in water (Figure 3), were calculated at $4.11 \mathrm{eV}$ in gas phase. For $\mathrm{Ag}_{10}$, two main bands are found both in solution and gas phase. They are centered at 3.12 and 3.95 $\mathrm{eV}$ in solution compared to 3.45 and $4.17 \mathrm{eV}$ in gas phase (Figure 4). The absorption spectra of bare $\mathrm{Ag}_{20}$ cluster shows a main band centered at $3.80 \mathrm{eV}$, composed of several transitions at 3.59, 3.73, 3.76, 3.84 and $4.01 \mathrm{eV}$ respectively (Figure 5). This band is redshifted compared to the band calculated in gas phase at $4.09 \mathrm{eV}{ }^{53}$ The present redshift obtained for small clusters is consistent with the redshift measured for nanoparticles of $1.3 \mathrm{~nm}$ in solution compared to gas phase. ${ }^{29}$

The adsorption of one or several thiols on silver clusters leads to significant changes in the spectra with a broadening, damping and shift of the main bands together with a dispersion of the oscillator strengths on the states in all the visible and $\mathrm{UV}$ domain. For complexed $\mathrm{Ag}_{4}$, the position of the main transition near $2.8 \mathrm{eV}$ is little changed by the adsorption of thiols but the oscillator strength strongly decreases (Figure 2). For $\mathrm{Ag}_{8}$ and $\mathrm{Ag}_{10}$, in addition to the reduction of its oscillator strength, the main band is redshifted by about 0.6 and $0.3 \mathrm{eV}$ for $\mathrm{Ag}_{8}$ (from 3.85 down to $3.22 \mathrm{eV}$ ) and $\mathrm{Ag}_{10}$ (from 3.12 down to $2.85 \mathrm{eV}$ ) respectively. When increasing the number of adsorbed molecules, the spectra become very rich with many peaks well scattered on all the range of energy, at both low and high energies. In the case of $\mathrm{Ag}_{20}$, the adsorption of an unique thiol leads to a strong damping and broadening of the main band, but the plasmon-like behavior is preserved. When several molecules are adsorbed, the plasmon-like band is redshifted (from 3.80 down to about $3.25 \mathrm{eV}$ ), and the band is no longer isolated, it is surrounded by peaks at both low and high energies. The observed red-shift of the plasmon-like band can be explained by the negative charge on $\mathrm{Ag}_{n}$, due to the charge transfer which occurs from sulfur to silver atoms.

In Supplementary information, we give the absorption spectra of $\left(\mathrm{FC}_{6} \mathrm{H}_{4} \mathrm{~S}^{-}\right)_{m}-\mathrm{Ag}_{10}, m=1,2$, 
for several adsorption sites on the metal surface. The calculated spectra show a very weak dependence on the sites of adsorption.

Three types of excitations are expected: local transitions on silver clusters, on thiol molecules, and charge-transfer transitions between $\mathrm{Ag}_{n}$ and aromatic cycles. ${ }^{37}$ As an illustration, we show in Figure 6 the electron density difference between the excited and the ground states for the main peaks of the spectrum of $\left(\mathrm{FC}_{6} \mathrm{H}_{4} \mathrm{~S}^{-}\right)_{4}-\mathrm{Ag}_{8}$. Light grey (red online) regions correspond to the depletion of the electron density during the transition, while dark (blue online) regions correspond to an increase of the electron density. It appears that the low-energy excitations (below $3.5 \mathrm{eV}$ ) are due to transitions mainly localized on silver atoms without any significant participation of thiol molecules. All the other peaks (above $3.5 \mathrm{eV}$ ) are due to charge-transfer transitions from silver clusters, and $\mathrm{S}$ atoms in a relatively small contribution, to aromatic cycles. The very large number of such charge-transfer excitations is responsible of the dispersion of peaks in all the UV-visible domain.

\section{Discussion}

Experimentally, there is no doubt that the thiol ligand binds to silver atoms via the thiolate bond, $32,39,40$ but the molecular orientation on the surface can be questionable when the anchoring occurs on a preformed cluster. ${ }^{62}$ To investigate the influence of the molecular orientation on the optical response, we have tested structures in which the ligand binds to the silver cluster through the sulfur atom in a perpendicular manner ("up position" relative to the metal cluster). In Figure 7 we compare spectra of $\mathrm{Ag}_{8}$ and $\mathrm{Ag}_{20}$ complexed with ligands either in down position (the aromatic rings are in proximity with the metal cluster, case (a) in Figure 7), or into an upright position (case (b) in Figure 7). The spectra of $\left(\mathrm{FC}_{6} \mathrm{H}_{4} \mathrm{~S}^{-}\right)_{4}-\mathrm{Ag}_{8}$ and $\left(\mathrm{CH}_{3} \mathrm{C}_{6} \mathrm{H}_{4} \mathrm{~S}^{-}\right)-\mathrm{Ag}_{8}$ with ligand in position "up" show a broadening of the main band compared to the spectrum of the bare $\mathrm{Ag}_{8}$ due to a spatial symmetry breaking and a lift of the degeneracy, but the spectra are still plasmon-like and stay somewhat similar to that of the pure $\mathrm{Ag}_{8}$ cluster. Hence the spectrum of $\left(\mathrm{FC}_{6} \mathrm{H}_{4} \mathrm{~S}^{-}\right)_{4}-\mathrm{Ag}_{8}$ with 
ligands in position "up" strongly contrasts with the spectrum where ligands are in position "down" in which the interactions between silver atoms and the aromatic cycles lead to a scattering of the optical response on all the range of energy. When an unique ligand is adsorbed on $\operatorname{Ag}_{20}$ clusters, the plasmon-like behavior is still present whatever the orientation of the ligand. But if the ligand adopts a position "down", the plasmon band is strongly broadened and damped, while it is nearly unaffected when the ligand is in position "up". When several ligand bind $\operatorname{Ag}_{20}$ (6 and 10 ligands are considered in Figure 7), the spectrum is strongly modified with many new transitions above 3 $\mathrm{eV}$ whatever the position adopted by ligands. However, the plasmon band is still visible when the ligands adopt the position up, with a redshift of about $0.5 \mathrm{eV}$, whereas it almost disappears if thiol ligands are in position "down".

Figure 8 highlights the influence of the molecular orientation on the excitations. When the ligands adopt a flat-lying position in which the aromatic cycles are in contact with the metal atoms (case (a) in Figure 8), all the optical transitions result from a strong interaction between the metal cluster and the aromatic rings, and transitions are mainly associated to charge transfers from silver atoms to carbon atoms. In contrast, when the ligand adopts a upright position (case (b) in Figure 8), we can find local excitations on silver clusters without any contribution of thiols (excitations at 3.23 and $3.28 \mathrm{eV}$ ). This is the plasmon. The other transitions, either at lower energies or higher energies, are associated to charge transfers from the thiols (mainly from sulfur and with a less important participation of carbon atoms) to the metal cluster together with local excitations on silver cluster. In conclusion, the orientation of ligands modifies the shape of the spectra and also the type of excitations in the optical response.

The experimental spectra measured for the monolayer protected silver nanoparticles $\operatorname{Ag}_{44}(\mathrm{SR})_{30}{ }^{4-}$, where the ligand was $\mathrm{FC}_{6} \mathrm{H}_{4} \mathrm{~S}^{-}$and $\mathrm{CH}_{3} \mathrm{C}_{6} \mathrm{H}_{4} \mathrm{~S}^{-}$amongst others, show several distinct bands covering the $375-840 \mathrm{~nm}$ range of energy. ${ }^{29}$ In particular, the nanoparticles coated by 4-fluorothiophenol in solution present some peaks at $3.30,2.99,2.56,2.30,1.93$, and $1.48 \mathrm{eV}$, whereas the plasmon band is at $2.82 \mathrm{eV}$ in the solution. ${ }^{29}$ The multiplication of the peaks is due to the electronic influence of the ligands on the metal core. This experimental behavior is consistent with our present 
simulation in which the plasmon-like band in small silver clusters is damped when the clusters are coated by ligands and the spectra clearly show a transition from plasmon-like behavior to molecular-like behavior with the emergence of several bands at both low and high energies with the increasing coating. Our calculations attribute the emergence of the new peaks to charge-transfer excitations between the aryl thiols and silver atoms. The redshift of the remaining plasmon-like band with the increasing coating is also consistent with the experimental results on clusters of 1.3$2.7 \mathrm{~nm}$ in diameter. ${ }^{29,32}$ It can be explained by the increasing negative charge on $\mathrm{Ag}_{n}$, due to the charge transfer which occurs from sulfur to silver atoms.

In simulations, it is common to replace a thiol by a SH group in order to make the calculations more tractable. In Supplemental information, we compare the spectrum of $\left[\operatorname{Ag}_{8}(\mathrm{SH})_{4}\right]^{4-}$ to that of $\left(\mathrm{FC}_{6} \mathrm{H}_{4} \mathrm{~S}^{-}\right)_{4}-\mathrm{Ag}_{8}$. As expected, $\left[\mathrm{Ag}_{8}(\mathrm{SH})_{4}\right]^{4-}$ is a correct representation of the complex when the ligands are in an upright position, i.e. the spectrum of $\left[\mathrm{Ag}_{8}(\mathrm{SH})_{4}\right]^{4-}$ is similar to that of $\left(\mathrm{FC}_{6} \mathrm{H}_{4} \mathrm{~S}^{-}\right)_{4}-\mathrm{Ag}_{8}$ when ligand is in "up" position, and when the molecular orbitals implied in transitions present a strong sulfur character. But of course, the simplified model does not take into account the interaction between the aromatic cycles and the metal surface, and the spectrum of $\left[\mathrm{Ag}_{8}(\mathrm{SH})_{4}\right]^{4-}$ strongly differs from that of $\left(\mathrm{FC}_{6} \mathrm{H}_{4} \mathrm{~S}^{-}\right)_{4}-\mathrm{Ag}_{8}$ where the ligands adopt a flat-lying position. We also give spectra of $\left[\mathrm{Ag}_{20}(\mathrm{SH})_{6}\right]^{2-}$ and $\left[\mathrm{Ag}_{20}(\mathrm{SH})_{10}\right]^{2-}$ which lead to the similar conclusion, i.e. the substitution of aryl thiols by SH groups can be used to reproduce the effects of thiols anchored into an upright position when the excitations present a strong sulfur character without any significant contributions of aromatic thiols.

\section{Conclusion}

We have presented a theoretical study in the framework of the time-dependent density functional theory of the optical response of some aryl thiols coated silver clusters. Although the standing-up position in which the ligand binds to the silver cluster into a perpendicular manner is expected to be favored for large, fully covered metal clusters, thanks to intermolecular interactions, the clusters 
investigated in the present study, $\operatorname{Ag}_{n} n \leq 20$, are found to be too small to accept a full covering. Consequently, the intermolecular interaction can not stabilize the ligands in "up" position, and the ligand tends to adopt a flat-lying position in which the phenyl ring is in contact with the metal cluster. Our calculations show that the adsorption of aryl thiols, either in an upright position or in a downright position, on silver cluster leads to a red-shift of the plasmon-like band and the emergence of many new excitations associated to charge-transfer transitions between thiols and the metal cluster. These excitations present a strong sulfur character, but also a significant contribution of the aromatic cycles when the ligand adopt a flat-lying position. The substitution of the thiol molecule by a SH group is justified only when the molecule adopts an upright position and the excitations present no significant contributions of aromatic thiols. Future work could be devoted to extending the present calculations to larger metal clusters for which the full covering occurs with ligands into an upright position.

\section{Acknowledgement}

The authors thank the Pôle Scientifique de Modélisation Numérique (PSMN) at Lyon, France, and the GENCI-IDRIS(Grant i2014086864) center for generous allocation of computational time.

\section{Supporting Information Available}

The supporting information includes some absorption spectra of $\left(\mathrm{FC}_{6} \mathrm{H}_{4} \mathrm{~S}^{-}\right)_{m}-\mathrm{Ag}_{10}, m=1,2$, with several configurations (Figure S-1), some absorption spectra calculated with two different density functionals namely LC-M06L and $\omega$ B97X-D (Figure S-2), and some absorption spectra where the thiol molecules are substituted by SH groups (Figure S-3). This information is available free of charge via the Internet at http://pubs.acs.org. 


\section{References}

(1) Gao, S.; Chen, D.; Li, Q.; Ye, J.; Jiang, H.; Amatore, C.; Wang, X. Near-Infrared Fluorescence Imaging of Cancer Cells and Tumors Through Specific Biosynthesis of Silver Nanoclusters. Sientific Reports 2014, 4, 4384.

(2) Hu, M.; Chen, J. Y.; Li, Z. Y.; Au, L.; Hartland, G. V.; Li, X. D.; Marquez, M.; Y,; Xia, N. Gold Nanostructures: Engineering Their Plasmonic Properties For Biomedical Applications. Chem. Soc. Rev. 2006, 35, 1084-1094.

(3) Stamplecoskie, K. G.; Scaiano, J. C. Light Emitting Diode Irradiation Can Control the Morphology and Optical Properties of Silver Nanoparticles. J. Am. Chem. Soc. 2010, 132, 18251827.

(4) Noguez, C.; Sanchez-Castillo, A.; Hidalgo, F. Role of Morphology in the Enhanced Optical Activity of Ligand-Protected Metal Nanoparticles. J. Phys. Chem. Lett. 2011, 2, 1038-1044.

(5) Durante, N.; Fortunelli, A.; Broyer, M.; Stener, M. Optical Properties of Au Nanoclusters from TD-DFT Calculations. J. Phys. Chem. C 2011, 115, 6277-6282.

(6) Haberland, H. Looking From Both Sides. Nature 2013, 494, E1-E2.

(7) Scholl, J. A.; Koh, A. L.; Dionne, J. A. Quantum Plasmon Resonances of Individual Metallic Nanoparticles. Nature 2012, 483, 421-428.

(8) Harbich, W.; Fedrigo, F.; Buttet, J. The Optical-Absorption Spectra of Small Silver Clusters (N=8-39) Embedded in Rare-Gas Matrices. Z. Phys. D 1993, 26, 138-140.

(9) Tiggesbaumker, J.; Koller, L.; Meiwes Broer, K. H.; Liebsch, A. Blue Shift of The Mie Plasma Frequency in Ag Clusters and Particles. Phys. Rev. A 1993, 48, R1749-R1752.

(10) Cottancin, E.; Celep, G.; Lermé, J.; Pellarin, M.; Huntzinger, J. R.; Vialle, J. L.; Broyer, M. Optical Properties of Noble Metal Clusters as a Function of the Size: Comparison between Experiments and a Semi-Quantal Theory. Theor. Chem. Acc. 2006, 116, 514-523. 
(11) Aikens, C. M.; Li, S.; Schatz, G. C. From Discrete Electronic States to Plasmons: TDDFT Optical Absorption Properties of $\operatorname{Ag}_{n}(n=10,20,35,56,84,120)$ Tetrahedral Clusters. $J$. Phys. Chem. C 2008, 112, 11272-11279.

(12) Harb, M.; Rabilloud, F.; Simon, D.; Rydlo, A.; Lecoultre, S.; Conus, F.; Rodrigues, V.; Felix, C. Optical Absorption of Small Silver Clusters : $\operatorname{Ag}_{n},(n=4-22)$. J. Chem. Phys. 2008, 129, 194108.

(13) Tiago, M.; Idrobo, J.; Ogut, S.; Jellinek, J.; Chelikowsky, J. Electronic and Optical Excitations in $\operatorname{Ag}_{n}$ Clusters $(n=18)$ : Comparison of Density-Functional and Many-Body Theories. Phys. Rev. B 2009, 79, 155419.

(14) Wei, J.; Schaeffer, N.; Pileni, M.-P. Ag Nanocrystals: 1. Effect of Ligands on Plasmonic Properties. J. Phys. Chem. B 2014, 118, 14070-14075.

(15) Burgess, R. W.; Keast, V. J. TDDFT Study of the Optical Absorption Spectra of Bare Gold Clusters. J. Phys. Chem. C 2014, 118, 3194-3201.

(16) Bonacic-Koutecky, V.; Veyret, V.; Mitric, R. Ab Initio Study of The Absorption Spectra of $\operatorname{Ag}_{n}(n=58)$ Clusters. J. Chem. Phys. 2001, 115, 10450.

(17) Harb, M.; Rabilloud, F.; Simon, D. Optical Absorption of Silver Clusters: A Study of The Effective Potential Core Size. Chem. Phys. Lett. 2009, 476, 186-190.

(18) Lecoultre, S.; Rydlo, A.; Buttet, J.; Felix, C.; Gilb, S.; Harbich, W. Ultraviolet-Visible Absorption of Small Silver Clusters in Neon: $\operatorname{Ag}_{n}(n=19)$. J. Chem. Phys. 2011, 134, 184504.

(19) Fedrigo, S.; Harbich, W.; Buttet, J. Collective Dipole Oscillations in Small Silver Clusters Embedded in Rare-Gas Matrices. Phys. Rev. B 1993, 47, 10706-10715.

(20) Charlé, K.-P.; Konig, L.; Nepijko, S.; Rabin, I.; Schulze, W. The Surface Plasmon Resonance of Free and Embedded Ag-Clusters in the Size Range 1,5 nm < D < $30 \mathrm{~nm}$. Cryst. Res. Technol. 1998, 33, 1085-1096. 
(21) Kraperovich, V.; Kresin, V. V. Ultraviolet Photoabsorption Spectra of Silver and Gold Nanoclusters. Phil. Mag. 1998, 78, 385-396.

(22) Rabilloud, F. UV-Visible Absorption Spectra of Metallic Clusters From TDDFT Calculations. Eur. Phys. J. D 2013, 67, 18.

(23) Barcaro, G.; Broyer, M.; Durante, N.; Fortunelli, A.; Stener, M. Alloying Effects on the Optical Properties of AgAu Nanoclusters from TDDFT Calculations. J. Phys. Chem. C 2011, $115,24085-24091$.

(24) Cottancin, E.; Lermé, J.; Gaudry, M.; Pellarin, M.; Vialle, J. L.; Broyer, M. Size effects in the optical properties of $\mathrm{Au}_{n} \mathrm{Ag}_{n}$ embedded clusters. Phys. Rev. B 2000, 62, 5179-5185.

(25) Harb, M.; Rabilloud, F.; Simon, D. Structure and Optical Properties of Core-Shell Bimetallic $\mathrm{Ag}_{n} \mathrm{Ni}_{n}$ Clusters: Comparison With Pure Silver and Nickel Clusters. J. Chem. Phys. 2009, $131,174302$.

(26) Harb, M.; Rabilloud, F.; Simon, D. Structural, Electronic, Magnetic and Optical Properties of Icosahedral Silver-Nickel Nanoclusters. Phys. Chem. Chem. Phys. 2010, 12, 4246-4254.

(27) Heard, C. J.; Johnston, R. L. A theoretical Study of The Structures and Optical Spectra of Helical Copper-Silver Clusters. Phys. Chem. Chem. Phys. 2014, 16, 21039-21048.

(28) Gaudry, M.; Lermé, J.; Cottancin, E.; Pellarin, M.; Vialle, J. L.; Broyer, M.; B. Prével, M. T.; Mélinon, P. Optical Properties of $\left(\mathrm{Au}_{x} \mathrm{Ag}_{1-x}\right)_{n}$ Clusters Embedded in Alumina: Evolution With Size and Stoichiometry. Phys. Rev. B 2001, 64, 085407.

(29) Bakr, O. M.; Amendola, V.; Aikens, C. M.; Wenseleers, W.; Li, R.; Negro, L. D.; Schatz, C.; Stellacci, F. Silver Nanoparticles with Broad Multiband Linear Optical Absorption. Angew. Chem. Int. Ed. 2009, 48, 5921-5926.

(30) Wu, Z.; Lanni, E.; Chen, W.; Bier, M. E.; Ly, D.; Jin, R. High Yield, Large Scale Synthesis of Thiolate-Protected $\mathrm{Ag}_{7}$ Clusters. J. Am. Chem. Soc. 2009, 131, 16672-16674. 
(31) Negishi, Y.; Sakamoto, C.; Ohyama, T.; Tsukuda, T. Synthesis and the Origin of the Stability of Thiolate-Protected $\mathrm{Au}_{130}$ and $\mathrm{Au}_{187}$ Clusters. J. Phys. Chem. Lett. 2012, 3, 1624-1628.

(32) Farrag, M.; Thamer, M.; Tschurl, M.; Burgi, T.; Heiz, U. Preparation and Spectroscopic Properties of Monolayer-Protected Silver Nanoclusters. J. Phys. Chem. C 2012, 116, 80348043.

(33) Russier-Antoine, I.; Bertorelle, F.; Vojkovic, M.; Rayane, D.; Salmon, E.; Jonin, C.; Dugourd, P.; Antoine, R.; Brevet, P.-F. Non-Linear Optical Properties of Gold Quantum Clusters. The smaller The Better. Nanoscale 2014, 6, 13572-13578.

(34) Chakraborty, I.; Mahata, S.; Mitra, A.; De, G.; Pradeep, T. Controlled Synthesis and Characterization of The Elusive Thiolated Ag $_{55}$ cluster. Dalton Trans. 2014, 43, 17904-17907.

(35) Chin, P. T. K.; van der Linden, M.; van Harten, E. J.; Barndregt, A.; Rood, M. T. M.; Koster, A. J.; van Leeuwen, F. W. B.; de Mello Donega, C.; Heck, A. J. R.; Meijerink, A. Enhanced Luminescence of Ag Nanoclusters Via Surface Modification. Nanotechnology 2013, $24,075703$.

(36) Fihey, A.; Maurel, F.; Perrier, A. Modeling the Absorbance Properties of a Pyrene Chromophore Grafted onto a $\mathrm{Au}_{25}$ Nanocluster: A TD-DFT Study. J. Phys. Chem. C 2014, 118, 4444-1153.

(37) Harb, M.; Rabilloud, F.; Simon, D. Optical Response of Silver Nanoclusters Complexed With Aromatic Thiol Molecules: A Time-Dependent Density-Functional Study. J. Phys. B: At. Mol. Opt. Phys. 2011, 44, 035101.

(38) Harkness, K. et al. $\operatorname{Ag}_{44}(\mathrm{SR})_{30}{ }^{4-}$ : A Silver-Thiolate Superatom Complex. Nanoscale 2012, 4, 4269-4274.

(39) Desireddy, A.; Conn, B. E.; Yoon, B.; Barnett, R. N.; Monahan, B. M.; Kirschbaum, K.; 
Griffith, W. P.; Whetten, R. L.; Landman, U.; Biogini, T. P. Ultrastable Silver Nanoparticles. Nature 2013, 501, 399-402.

(40) Yang, H.; Wang, Y.; Huang, H.; Gell, L.; Lehtovaara, L.; Malola, S.; Hakkinen, H.; Zheng, N. All-Thiol-Stabilized $\mathrm{Ag}_{44}$ and $\mathrm{Au}_{12} \mathrm{Ag}_{32}$ Nanoparticles With Single-Crystal Structures. $\mathrm{Na}$ ture Communications 2013, 4, 2422.

(41) Gell, L.; Hakkinen, H. Theoretical Analysis of The $\mathrm{M}_{12} \mathrm{Ag}_{32}(\mathrm{SR})_{40}{ }^{4-}$ and $\mathrm{X} @ \mathrm{M}_{12} \mathrm{Ag}_{32}(\mathrm{SR})_{40}{ }^{4-}$ Nanoclusters $(\mathrm{M}=\mathrm{Au}, \mathrm{Ag} ; \mathrm{X}=\mathrm{H} ; \mathrm{Mn})$. DOI:10.1021/jp510926q. $J$. Phys. Chem. C 2015,

(42) Yang, H.; Wang, Y.; Yan, J.; Chen, X.; Zhang, X.; Hakkinen, H.; Zheng, N. Structural Evolution of Atomically Precise Thiolated Bimetallic $\left[\mathrm{Au}_{12+n} \mathrm{Cu}_{32}(\mathrm{SR})_{30+n}\right]^{4-}(n=0,2,4,6)$ Nanoclusters. J. Am. Chem. Soc. 2014, 136, 7197-7200.

(43) Runge, E.; Gross, E. K. U. Density-Functional Theory for Time-Dependent Systems. Phys. Rev. Lett. 1984, 52, 997-1000.

(44) van Leeuwen, R. Key Concepts in Time-Dependent Density-Functional Theory. Int. J. Mod. Phys. B 2001, 15, 1969-2023.

(45) Casida, M. E. Time-Dependent Density-Functional Response Theory For Molecules in Recent Advances in Density Functional Methods. Part I, p. 155; D.P. Chong Ed. (Singapore, World Scientific), 1995.

(46) Frisch, M. J. et al. Gaussian09 Revision D.01. Gaussian Inc. Wallingford CT 2009.

(47) Allouche, A. R. Gabedit A Graphical User Interface For Computational Chemistry Softwares. J. Comput. Chem. 2011, 32, 174-182.

(48) Andrae, D.; Haussermann, U.; Dolg, M.; Stoll, H.; Preuss, H. Energy-Adjusted Ab Initio pseudopotentials For The Second and Third Row Transition Elements. Theor. Chim. Acta 1990, 77, 123-141. 
(49) Dunning Jr., T. H.; Hay, P. J. in Modern Theoretical Chemistry, Vol. 3, p. 1-28; H. F. Schaefer III Ed. (Plenum, New York), 1977.

(50) Weigend, F.; Ahlrichs, R. Balanced Basis Sets of Split Valence, Triple Zeta Valence and Quadruple Zeta Valence Quality For H to Rn: Design and Assessment of Accuracy. Phys. Chem. Chem. Phys. 2005, 7, 3297-3305.

(51) Iikura, H.; Tsuneda, T.; Yanai, T.; Hirao, K. A Long-Range Correction Scheme For Generalized-Gradient-Approximation Exchange Functionals. J. Chem. Phys. 2001, 115, $3540-3544$.

(52) Zhao, Y.; Truhlar, D. G. A New Local Density Functional For Main-Group Thermochemistry, Transition Metal Bonding, Thermochemical Kinetics, and Noncovalent Interactions. J. Chem. Phys. 2006, 125, 194101.

(53) Rabilloud, F. Assessment of The Performance of Long-Range-Corrected Density Functionals For Calculating The Absorption Spectra of Silver Clusters. J. Phys. Chem. A 2013, 117, 4267-4278.

(54) Rabilloud, F. Description of Plasmon-Like Band in Silver Clusters: The Importance of The Long-Range Hartree-Fock Exchange in Time-Dependent Density-Functional Theory Simulations. J. Chem. Phys. 2014, 141, 144302.

(55) Chai, J.-D.; Head-Gordon, M. Long-range corrected hybrid density functionals with damped atom-atom dispersion corrections. Phys. Chem. Chem. Phys. 2008, 10, 6615-6620.

(56) Mertius, S.; Scrocco, E.; Tomassi, J. Electrostatic Interaction of A Solute With A Continuum. A Direct Utilization of Ab Initio Molecular Potentials For the Prevision of Solvent Effects. Chem. Phys. 1981, 55, 117-129.

(57) Cossi, M.; Rega, N.; Scalmani, G.; Barone, V. Energies, Structures, and Electronic Properties 
of Molecules in Solution With the C-PCM Solvation Model. J. Comp. Chem. 2003, 24, 669681.

(58) Dunlap, B. I. Robust and Variational Fitting: Removing The Four-Center Integrals From Center Stage in Quantum Chemistry. J. Mol. Struct (TEOCHEM) 2000, 529, 37-40.

(59) Eichkorn, K.; Treutler, O.; Ohm, H.; Haser, M.; Ahlrichs, R. Auxiliary Basis Sets to Approximate Coulomb Potentials. Chem. Phys. Lett. 1995, 240, 283-289.

(60) Eichkorn, K.; Weigend, F.; Treutler, O.; Ahlrichs, R. Auxiliary Basis Sets For Main Row Atoms and Transition Metals and Their Use to Approximate Coulomb Potentials. Theor. Chem. Acc. 1997, 97, 119-124.

(61) Reed, A. E.; Weinstock, R. B.; Weinhold, F. Natural Population Analysis. J. Chem. Phys. 1985, 83, 735-746.

(62) Cabalo, J.; Guicheteau, J. A.; Christesen, S. Toward Understanding the Influence of Intermolecular Interactions and Molecular Orientation on the Chemical Enhancement of SERS. $J$. Phys. Chem. A 2013, 117, 9028-9038. 

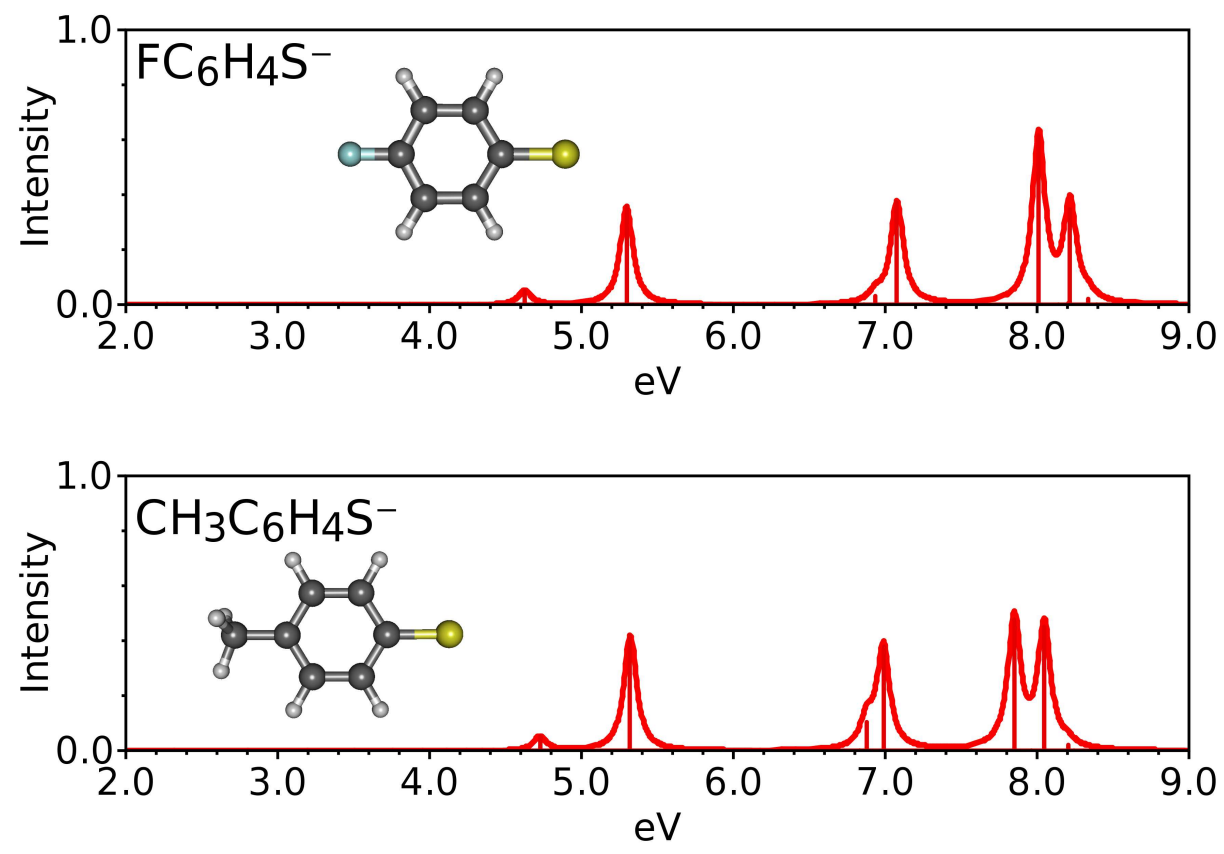

Figure 1: Absorption spectra of $\mathrm{FC}_{6} \mathrm{H}_{4} \mathrm{~S}^{-}$and $\mathrm{CH}_{3} \mathrm{C}_{6} \mathrm{H}_{4} \mathrm{~S}^{-}$. 

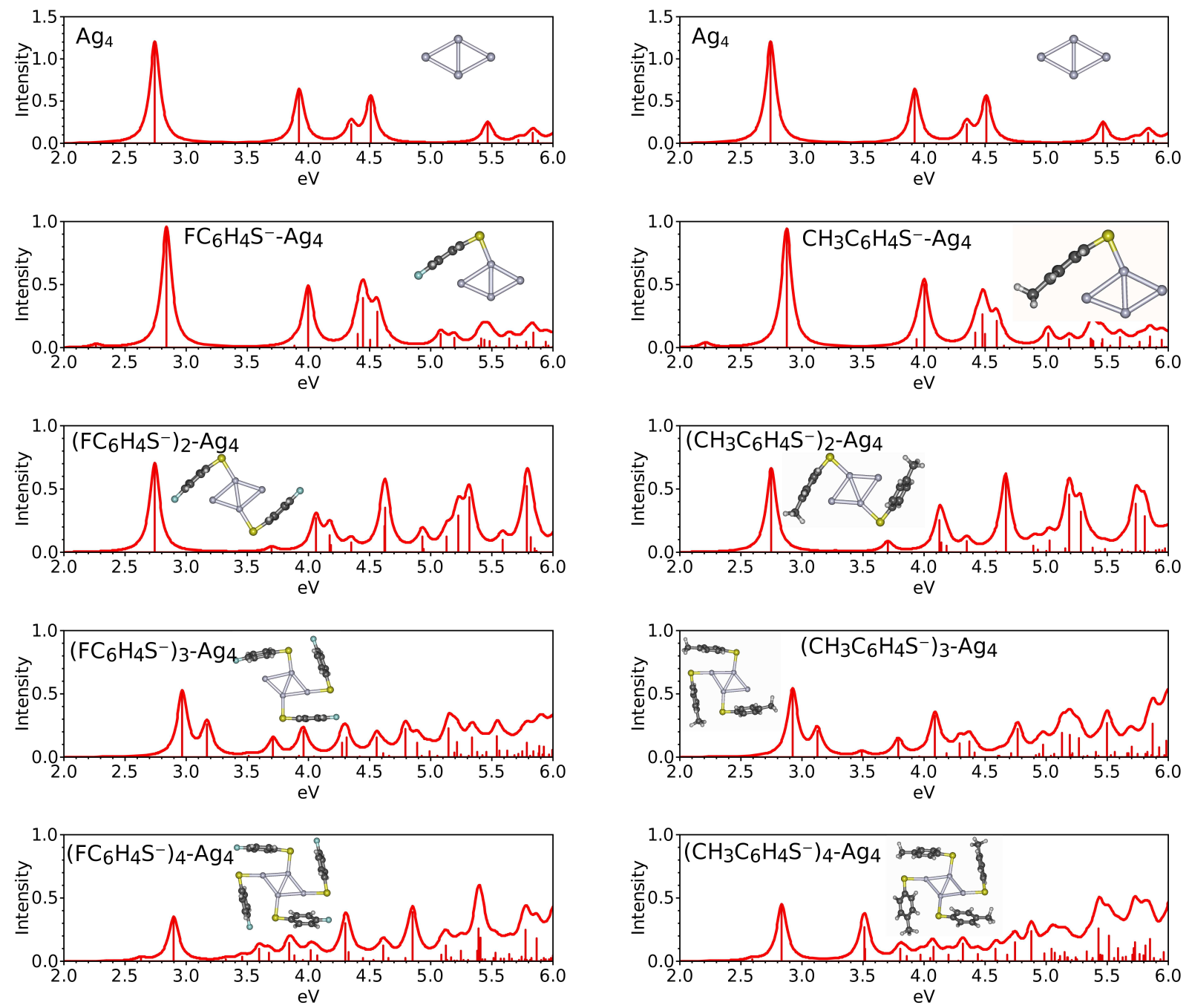

Figure 2: Evolution of the absorption spectra of $\left(\mathrm{FC}_{6} \mathrm{H}_{4} \mathrm{~S}^{-}\right)_{m}-\mathrm{Ag}_{4}$ and $\left(\mathrm{CH}_{3} \mathrm{C}_{6} \mathrm{H}_{4} \mathrm{~S}^{-}\right)_{m}-\mathrm{Ag}_{4}$ complexes as a function of the number of adsorbed molecules. 

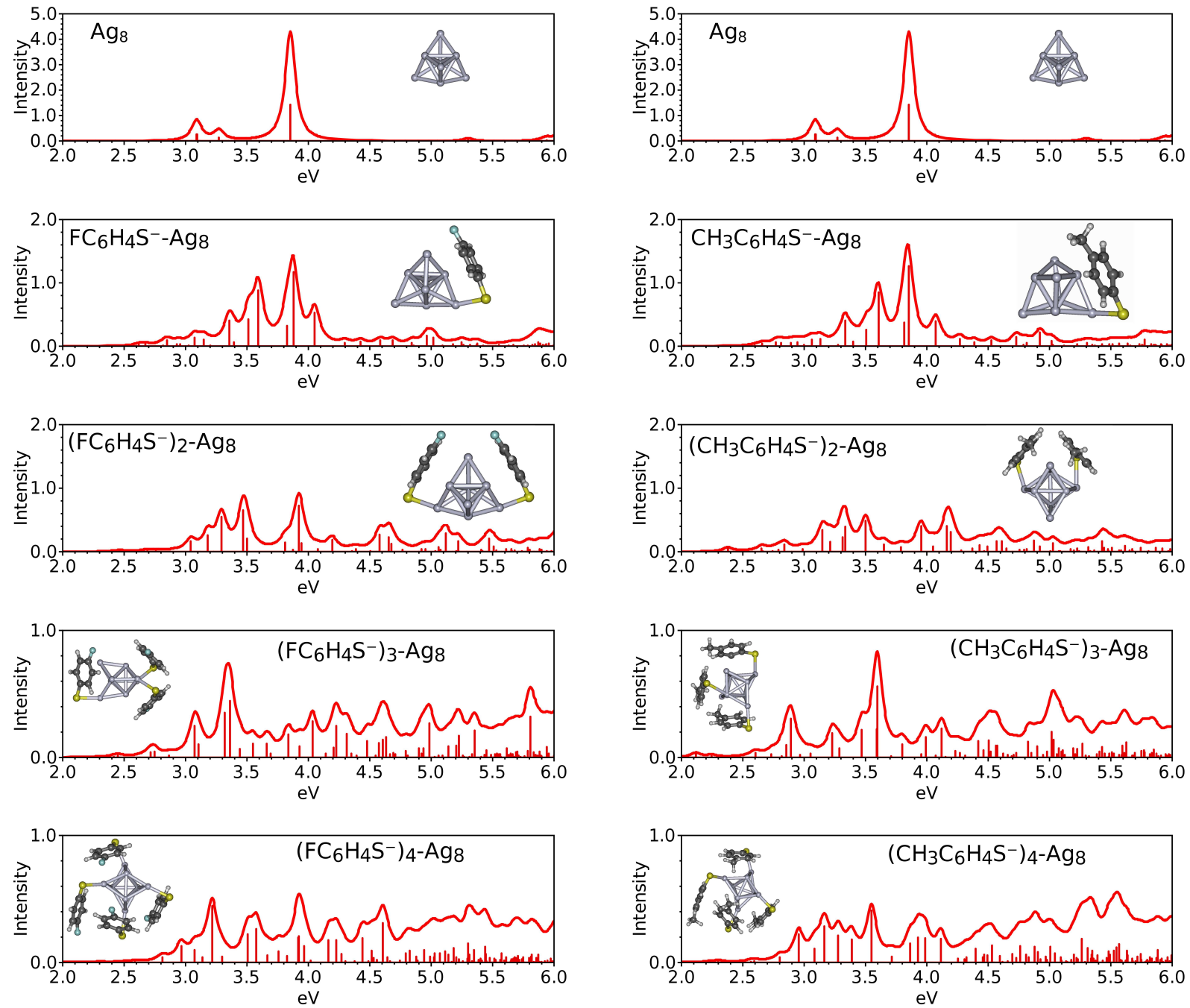

Figure 3: Evolution of the absorption spectra of $\left(\mathrm{FC}_{6} \mathrm{H}_{4} \mathrm{~S}^{-}\right)_{m}-\mathrm{Ag}_{8}$ and $\left(\mathrm{CH}_{3} \mathrm{C}_{6} \mathrm{H}_{4} \mathrm{~S}^{-}\right)_{m}-\mathrm{Ag}_{8}$ complexes as a function of the number of adsorbed molecules. 

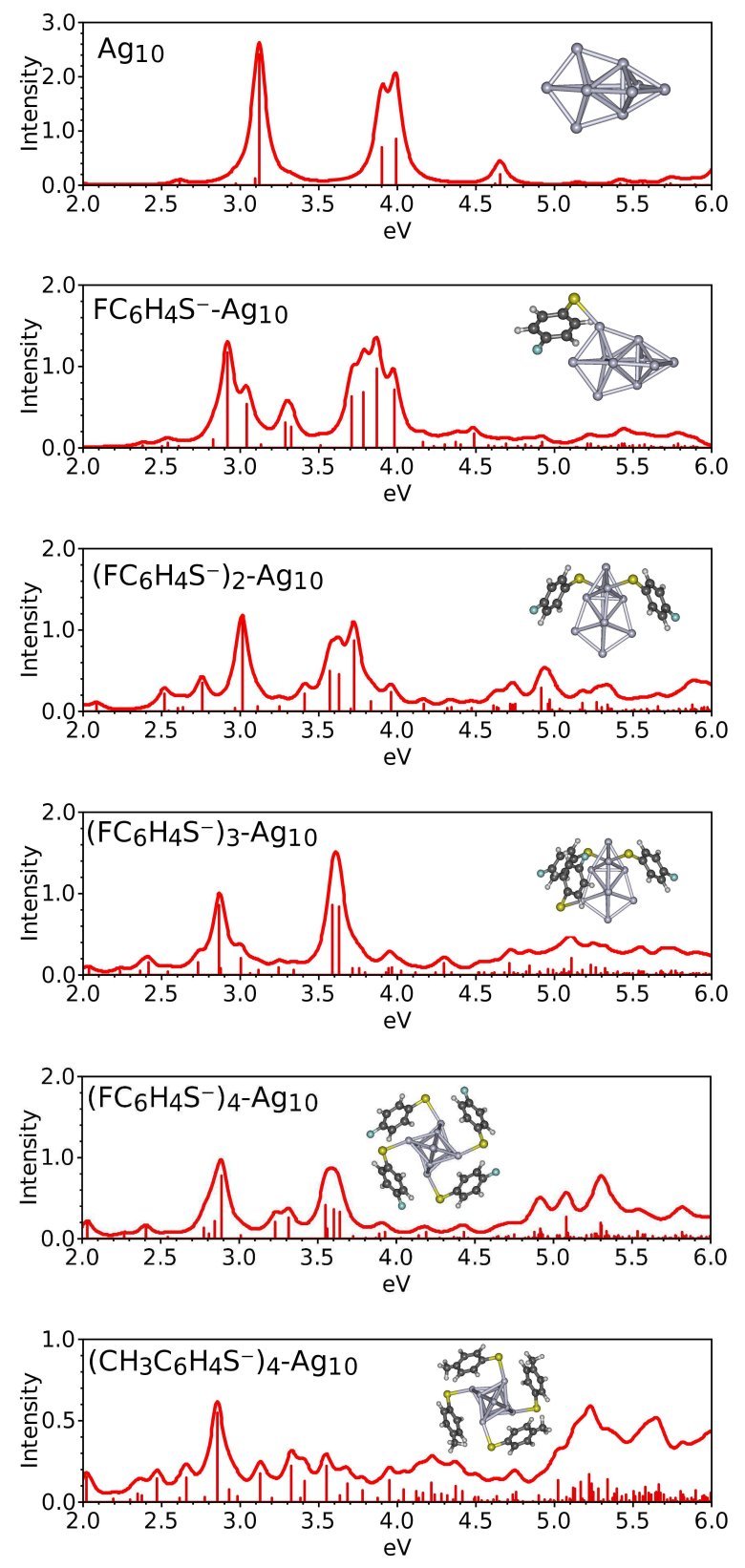

Figure 4: Evolution of the absorption spectra of $\left(\mathrm{FC}_{6} \mathrm{H}_{4} \mathrm{~S}^{-}\right)_{m}-\mathrm{Ag}_{10}$ and $\left(\mathrm{CH}_{3} \mathrm{C}_{6} \mathrm{H}_{4} \mathrm{~S}^{-}\right)_{m}-\mathrm{Ag}_{10}$ complexes as a function of the number of adsorbed molecules. 

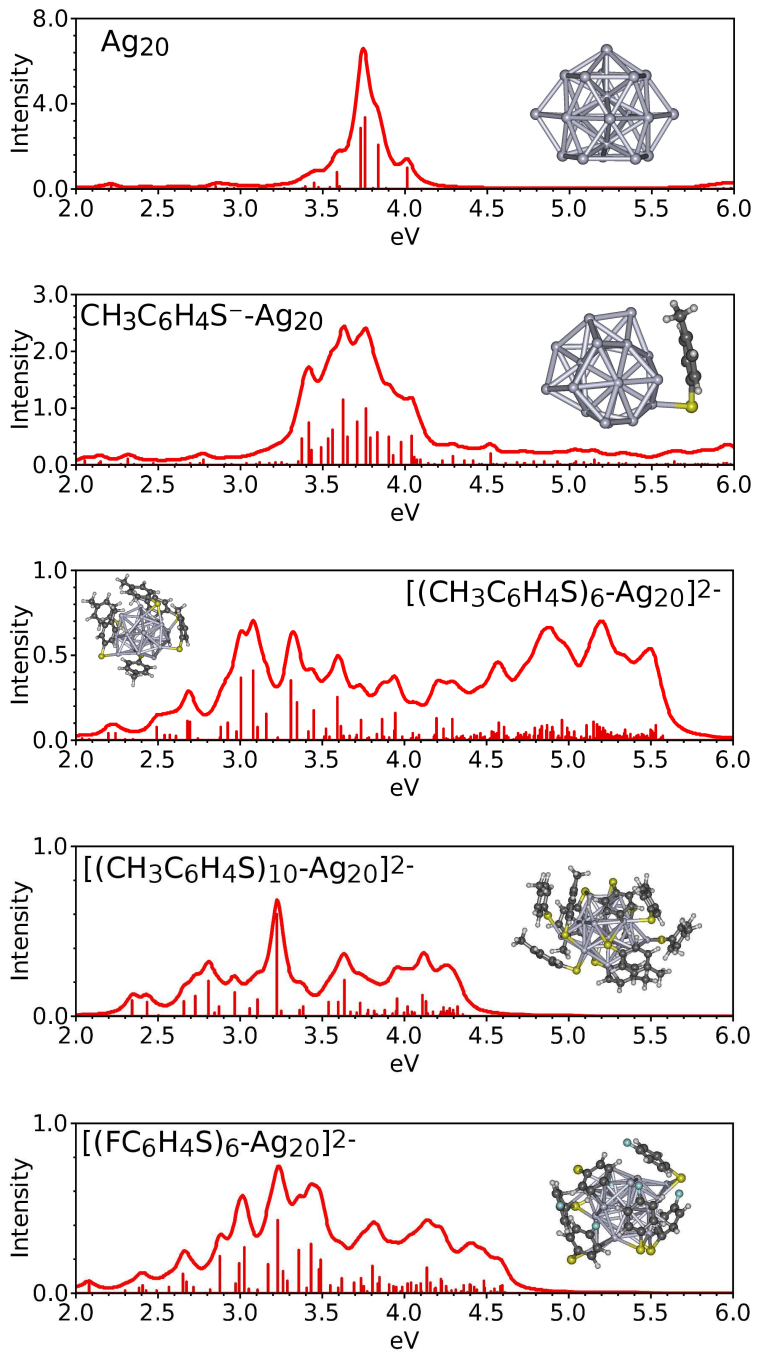

Figure 5: Absorption spectra of $\left[\left(\mathrm{CH}_{3} \mathrm{C}_{6} \mathrm{H}_{4} \mathrm{~S}\right)_{m}-\mathrm{Ag}_{20}\right]^{2-}, m=1,6,10$, and $\left[\left(\mathrm{FC}_{6} \mathrm{H}_{4} \mathrm{~S}\right)_{6}-\mathrm{Ag}_{20}\right]^{2-}$. 


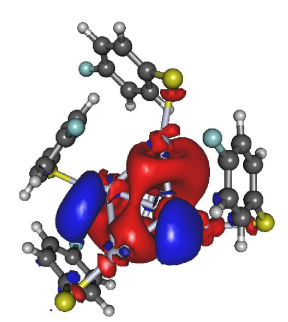

$2.97 \mathrm{eV}$

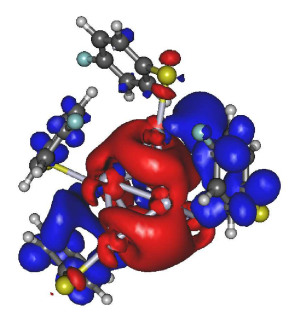

$3.92 \mathrm{eV}$

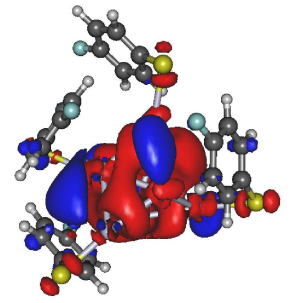

$3.22 \mathrm{eV}$

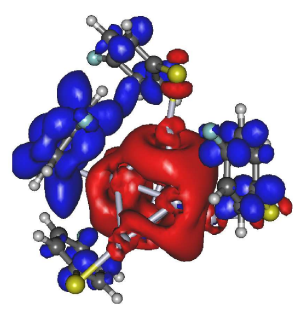

$4.18 \mathrm{eV}$

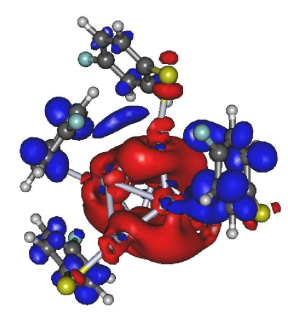

$3.51 \mathrm{eV}$

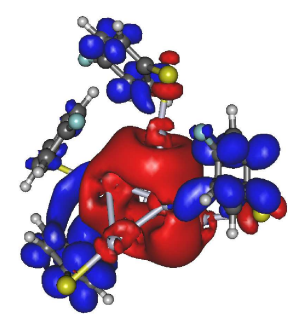

$4.22 \mathrm{eV}$

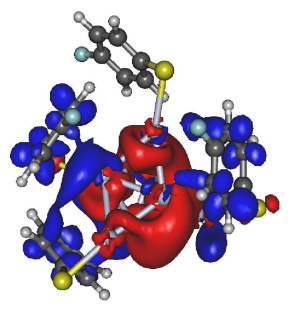

$3.58 \mathrm{eV}$

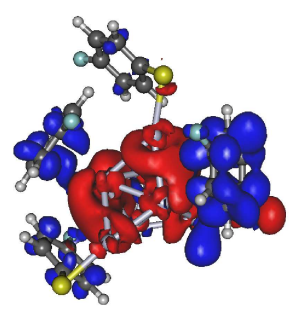

$4.44 \mathrm{eV}$

Figure 6: Isosurface of the electron density difference between the excited and ground states for some of the main peaks of $\left(\mathrm{FC}_{6} \mathrm{H}_{4} \mathrm{~S}^{-}\right)_{4}-\mathrm{Ag}_{8}$ clusters. Red colored regions correspond to the depletion of the electron density during the transition while the blue regions correspond to the accumulation of electrons. 
This material is available free of charge via the Internet at http://pubs.acs.org/. 
(a)
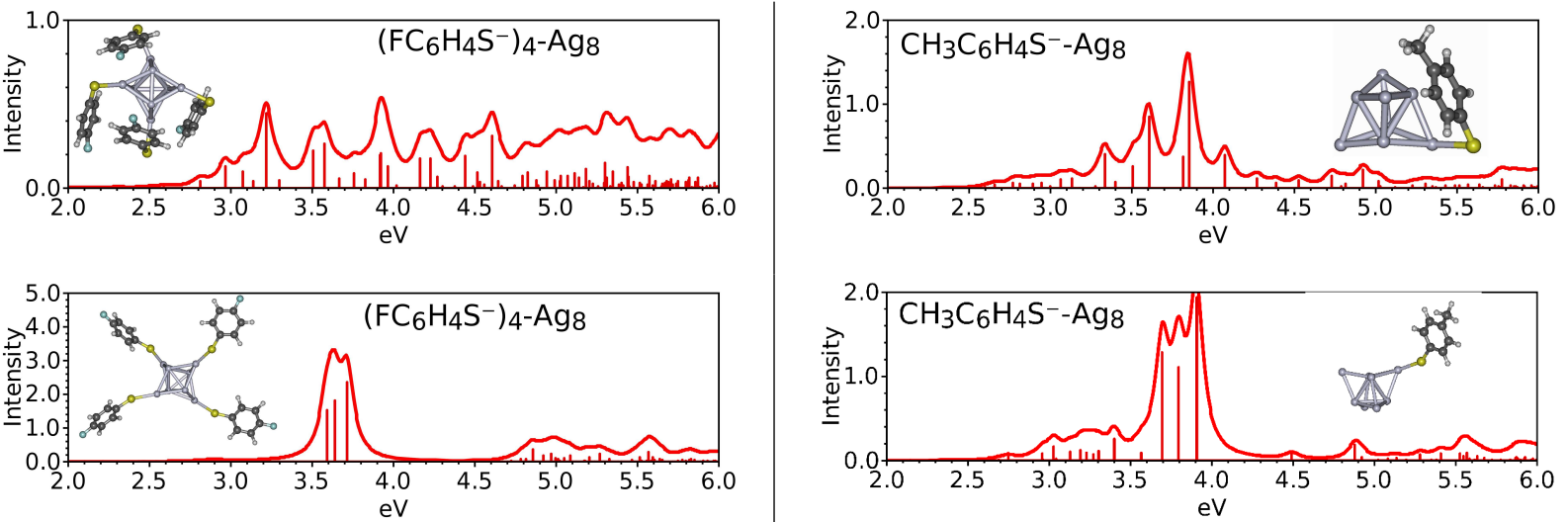

(b)
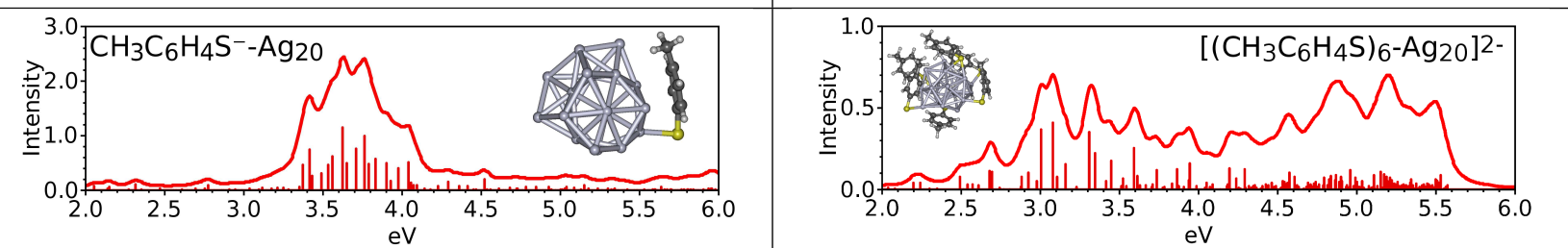

(a)
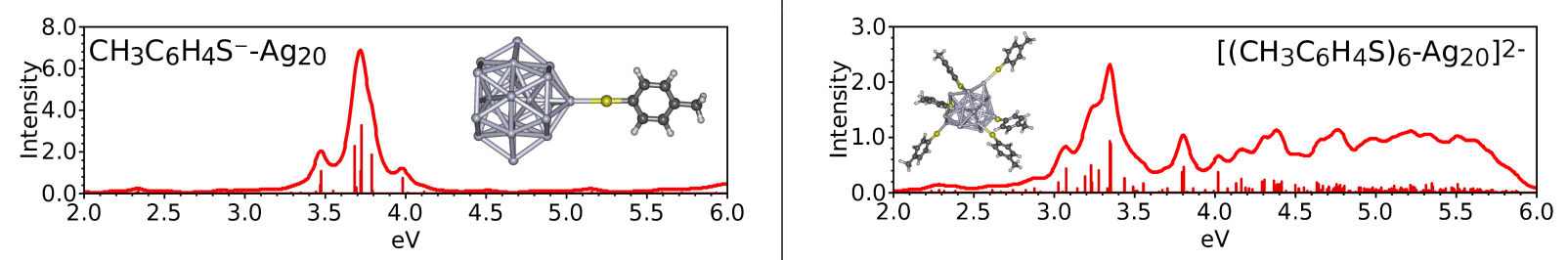

(b)

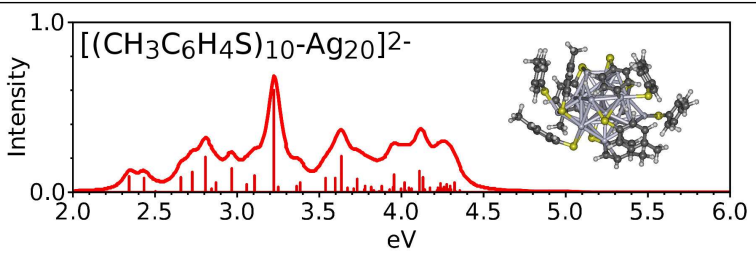

(a)

(b)

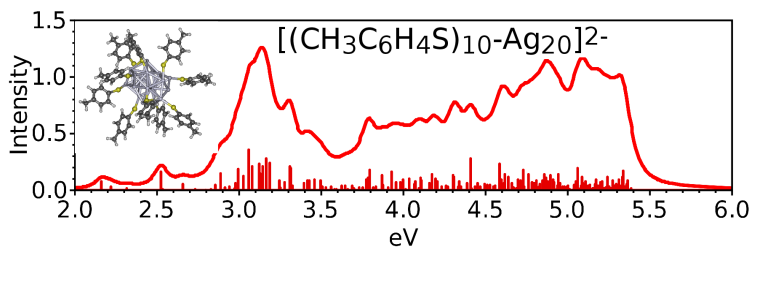

Figure 7: Effects of the molecular orientation on the absorption spectra. The thiol ligands are either in a down position in which the aromatic rings are in proximity with the metal cluster (a), or into an upright position (b). 


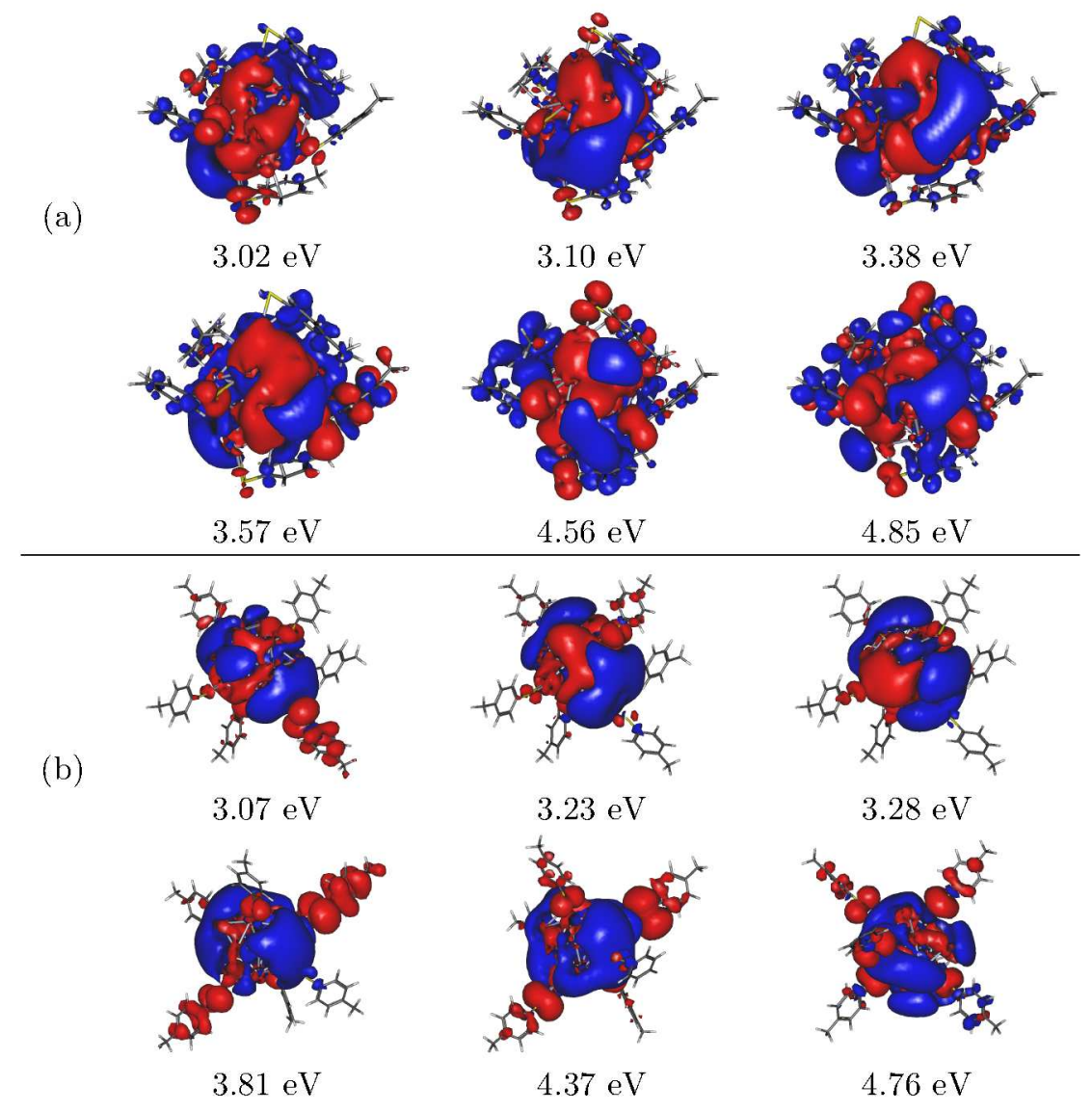

Figure 8: Isosurface of the electron density difference between the excited and ground states for some representative peaks of $\left[\left(\mathrm{CH}_{3} \mathrm{C}_{6} \mathrm{H}_{4} \mathrm{~S}\right)_{6}-\mathrm{Ag}_{20}\right]^{2-}$ cluster in two different configurations: the thiol ligands are either in a down position in which the aromatic rings are in proximity with the metal cluster (a), or into an upright position (b). Red colored regions correspond to the depletion of the electron density during the transition while the blue regions correspond to the accumulation of electrons. 


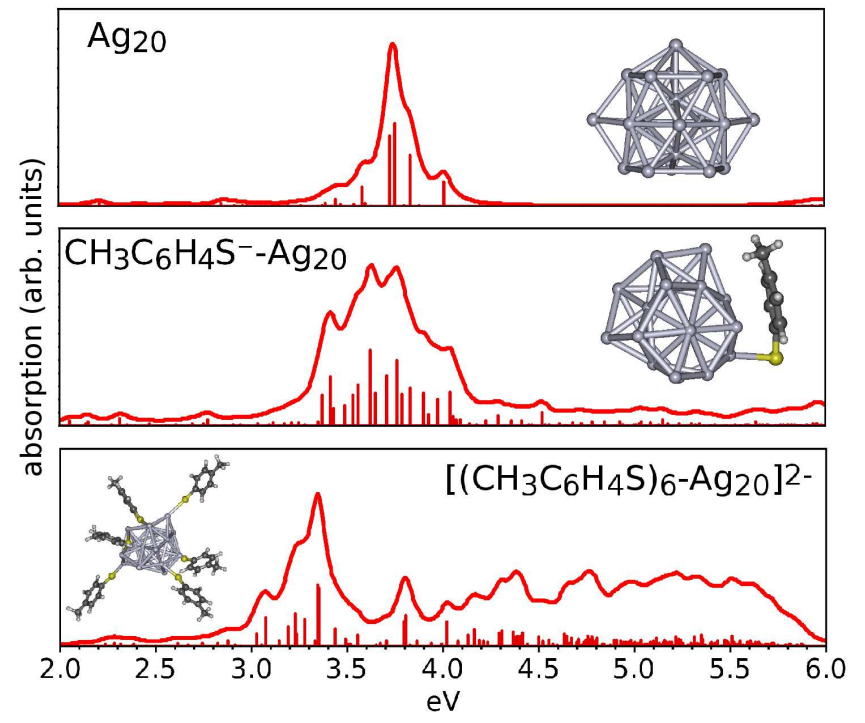

Table of Contents Graphic (TOC) 